
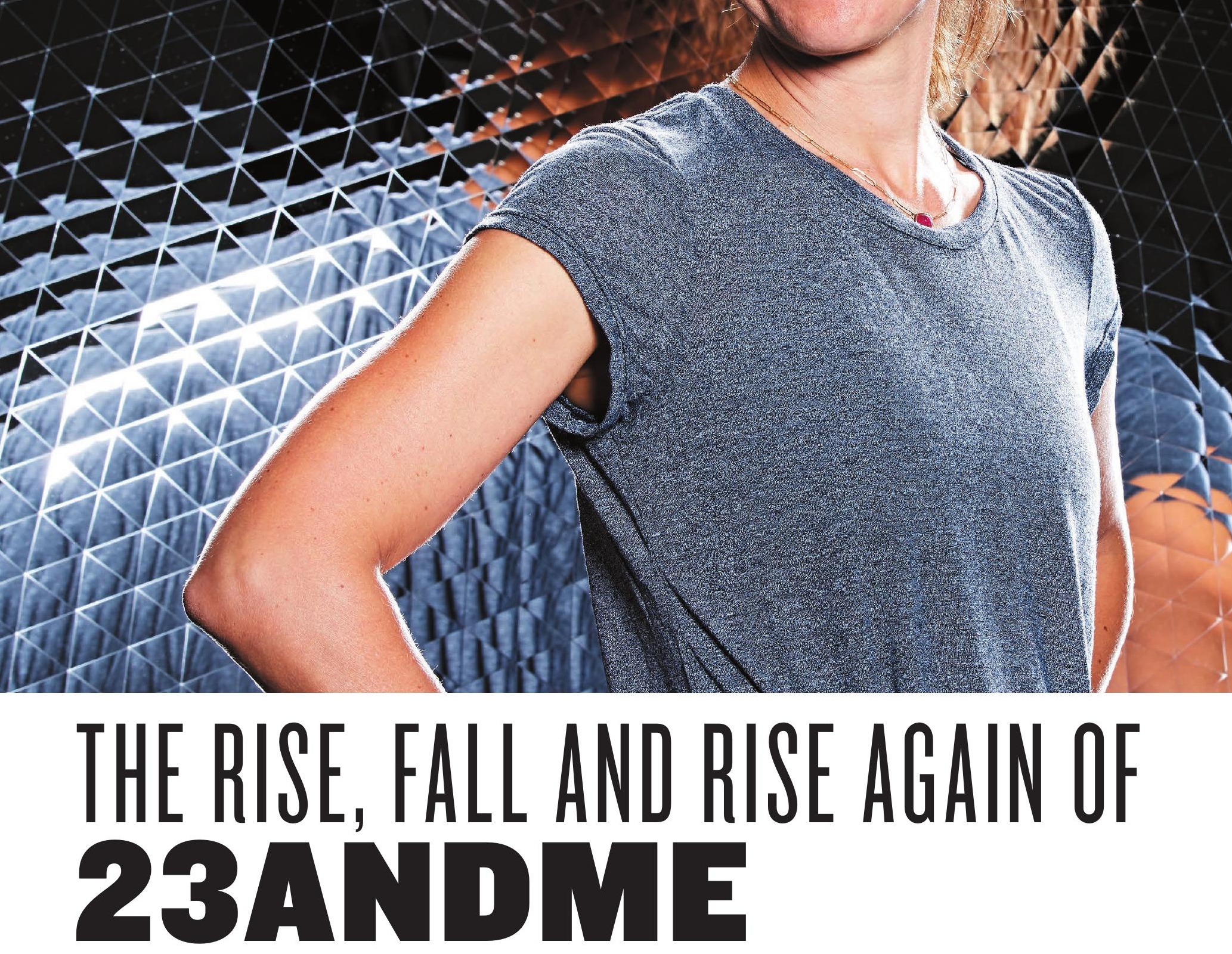

HOW ANNE WOJCICKI TOOK THE START-UP FIRM FROM THE BRINK OF FAILURE TO SCIENTIFIC PRE-EMINENCE. 
Anne Wojcicki founded the consumer-genetics firm 23andme in 2006 and aims to expand its customer base to 10 million.
Alzheimer's disease. Surfing a wave of positive news, the company has since launched an advertising blitz to dramatically expand its customer base to 10 million people.

23andme has always been the most visible face of direct-to-consumer genetic testing, and it is more formidable now than ever before. In September, the company announced that it had raised US\$250 million: more than the total amount of capital raised by the company since its inception. Investors estimate that it is worth more than $\$ 1$ billion, making it a 'unicorn' in Silicon Valley parlance - a rare and valuable thing to behold. But for scientists, 23andme's real worth is in its data. With more than 2 million customers, the company hosts by far the largest collection of gene-linked health data anywhere. It has racked up 80 publications, signed more than 20 partnerships with pharmaceutical firms and started a therapeutics division of its own.

"They have quietly become the largest genetic study the world has ever known," says cardiologist Euan Ashley at Stanford University, California.

But as it matures, 23andme faces new challenges. It must sustain customers' trust, fight off competition and prove that it can use genetic data to make new medicines - a notoriously difficult goal. And 23 andme still has a long way to go with the FDA, which won't allow it to tell customers many genetic results directly relevant to human health, such as those for the BRCA genes, which are linked to breast cancer.

Still, Wojcicki is undeterred. "I'm very stubborn," she says.

\section{IN THE PICTURE}

23andme's headquarters in Mountain View, California, have a startup vibe that belies the company's 11-year history. Pink and green foil balloons float over cubicles to commemorate employees' work anniversaries. The kitchenette is stocked with healthy snacks. And Polaroid photographs of all employees line the wall of the free cafeteria. Each

\section{"THEY HAVE QUIETLY BECOME THE LARGEST GENETIC STUDY THE WORLD HAS EVER KNOWN."}

picture is scrawled with a quirky fact about the person. ("Her favorite drink is green tea," reads one. "Once won a lip-sync contest singing a New Kids on the Block song," boasts another.) Arranged by the order in which employees joined the company, the photos make clear where everyone fits in.

The first photo, of course, is of Wojcicki, who grew up on the campus of Stanford University, the child of a teacher and a physics professor. She majored in biology at Yale University in New Haven, Connecticut, where she played ice hockey. (She's still an avid athlete; the bike she rides to work is often parked in 23 andme's lobby.)

In 1996, after graduating, Wojcicki worked for investment companies and hedge funds analysing heath-care ventures. She eventually came to dislike how the industry incentivized the development of expensive products and services that earn maximum insurance payments, rather than treatments and devices that consumers can afford to pay for on their own.

Wojcicki founded 23andme in 2006 with Linda Avey and Paul Cusenza with a goal of upending conventional models of health care. The following year, it received $\$ 8.95$ million from a number of high-powered investors, including the biotechnology powerhouse Genentech in South San Francisco and Google, whose co-founder Sergey Brin was married to Wojcicki from 2007 to 2015.

Wojcicki aimed to attract millions of customers by selling an ten medical conditions, including Parkinson's disease and late-onset 
inexpensive test that would reveal genetic predispositions for dozens of traits. It would provide disease risks, but also genetic propensity for baldness, obesity and trivial features such as earwax consistency. Wojcicki wanted to make the genome fun and engaging, the better to attract customers. She hosted celebrity 'spit' parties to get the product in the hands of tastemakers and stir up media interest: after taking one of the company's tests, Ivanka Trump gloated that she had a very low genetic risk of becoming obese. As the tests hit the market in late 2007, Wojcicki and Avey were hailed as visionaries (Cusenza had left in 2007; Avey would depart in 2009).

Scientists, meanwhile, were dubious. Family history was and is still a more powerful indicator than genes are for predicting the risk of most diseases. "The evidence is increasingly strong that the benefits of direct-to-consumer testing for these kinds of indications are somewhere between small and zero," says Stanford University lawyer and ethicist Hank Greely, a long-time critic of the company.

There were also questions about 23andme's plan to sell customer data to help develop medicines. Companies have been trying to mine genetic data to design drugs for at least a decade, with little success. Take deCODE genetics, founded in Reykjavik in 1996, which recruited about half of the adult population of Iceland into a genetic study. Although the company's research has provided insights into the genetic mechanisms of disease, it hasn't yet yielded a drug.

Scientists' scepticism didn't deter hundreds of thousands of customers from signing up to 23 andme, nor did it stop investors from ploughing $\$ 118$ million into the company in its first five years - but a problem was emerging in the background. In 2009, the FDA started asking 23andme for evidence that the company's products worked as advertised and wouldn't harm customers. The agency was worried that people might take drastic medical measures on the basis of their test results, such as deciding to change the dosage of their medications without consulting a doctor or undergoing unnecessary surgery, such as a mastectomy, or treatment based on false positives. Regulators demanded evidence that the tests were accurate, and that customers were well informed what the results meant.

The next years were difficult ones for 23 andme. It communicated with the agency on a few occasions and promised in January 2013 that data would be forthcoming. According to the FDA, it then ceased communicating with regulators entirely in May, even as it started a new advertising campaign. Fed up, the agency sent Wojcicki a strongly worded warning letter on 22 November 2013 ordering her company to stop marketing its product.

It was a self-inflicted wound for the company. "There was a bit of arrogance," says Richard Scheller, who was an executive at Genentech at the time. As a result, 23andme was forced to drastically cut its customer offerings, threatening its viability.

Wojcicki was stunned. "It became clear that we had pissed them off," she says. "I really didn't know that we had done so many things that angered them."

\section{BACK ON TRACK}

Soon after the letter arrived, Wojcicki called Kathy Hibbs, a lawyer then working for Genomic Health, a gene-testing company in nearby Redwood City, California.

"Can I get my whole company back in one year?" Wojcicki asked Hibbs.

"You can get it back, but it will take years," Hibbs replied. And to get there, she counselled, Wojcicki would have to cooperate with regulators.

It was a tough adjustment for Wojcicki; she didn't think that the FDA should be able to stop customers from learning their own genetic information. But Hibbs and others convinced her that capitulating to the FDA's demands was the fastest way to rescue her company.

"It's almost like being in a relationship," Wojcicki says. "There's things that you might disagree with, but you just have to do them." Wojcicki hired Hibbs, who began gathering evidence to respond to the FDA's concerns - a formidable task, because the FDA and the company had

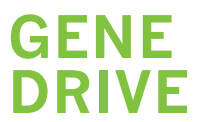

The direct-to-consumer genetic-testing industry is predicted to grow to US\$340 million in the next five years. This is still a small fraction of the overall market for DNA testing, which is expected to reach $\$ 10$ billion in that time.

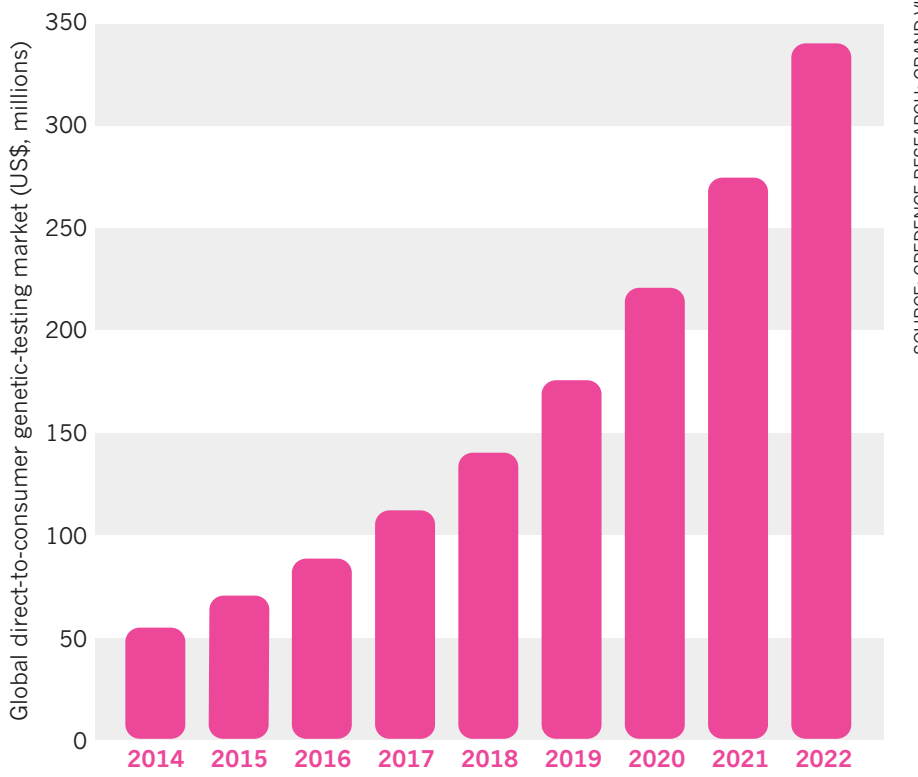

tussled over many issues over the years. By the end of 2014, Hibbs felt that the company was ready, so she asked the FDA to approve one test, intended to tell customers whether their children might inherit a genetic risk for a disease called Bloom syndrome.

The FDA approved the test in February 2015. The news didn't make a huge public splash: Bloom syndrome is a very rare disorder, affecting about 1 in 50,000 people with Ashkenazi Jewish heritage. But 23andme was now the first company approved to market a direct-to-consumer genetic test for a disease in the United States, although it had already been offering the test overseas.

But even after the FDA's decision this April, 23andme is still barred from giving customers lots of available information, such as whether they carry gene variants that raise their risk for certain cancers or that predict how well certain medications will work. Before the FDA lockdown, it had been providing information on hundreds of health conditions.

Greely says that the restrictions make sense: there is very strong evidence that genetic variants cause the ten conditions listed in the FDA's approval in April. But the predictive value is much weaker for the variants linked to the vast majority of common health conditions that 23 andme would like to tell its customers about.

\section{PATHS OF DISCOVERY}

Even as the company confronted resistance at the FDA, it was making moves into drug development. Key to this plan was bringing Scheller aboard. Wojcicki e-mailed him on the day he announced his retirement from Genentech in December 2014. Four months later, Scheller arrived in Mountain View to start 23andme's therapeutics group; by July, Wojcicki had raised \$115 million more from investors.

Scheller was attracted not just by the size of 23 andme's database, but by its richness. Customers have each answered an average of 300 questions on a huge array of traits, including their medical histories. That enables Scheller's team to try a different approach for gene-driven drug development.

The standard method has been a genome-wide association study, or GWAS, in which scientists gather people with a disease or trait, and then look for gene variants that seem to contribute to it. Scheller's team can do the reverse. They start with a particular gene that known drugs target, and then look for the diseases or health traits - the phenotypes - that are associated most strongly with different variants in the gene. "We just let the database show us what to work on," Scheller says. 
It's a study design called a phenome-wide association study, or PheWAS - and Erik Karrer, director of drug discovery, calls it the company's "secret sauce". 23andme is banking that it will speed drug discovery by allowing scientists to select drug targets that are important in human biology, that can be targeted by drugs and that are less likely to cause side effects.

To see if it works, computational biologist Fah Sathirapongsasuti studied whether 23 andme's genetic and health data could predict the success of drugs developed over the past few decades. Sathirapongsasuti surveyed a database of thousands of drug compounds, some of which were approved for sale by regulators.

He compiled a list of all the genes encoding proteins targeted by drugs in this database, and compared it against variations in these genes among 23 andme's customers, checking to see what medical conditions they had reported to the company. The process helped to validate the genetic basis for some drugs in humans in a way that mouse studies and other preclinical research often can't. Sathirapongsasuti also found instances in which 23 andme customer data correctly predicted side effects of approved drugs.

And the data were able to predict which drugs approved for some conditions might work better for others. Isofagomine tartrate, for instance, was initially intended to treat Gaucher's disease, a rare genetic disorder, but it stalled after a failed clinical trial in 2009. Sathirapongsasuti's data suggest that the drug might also affect the processes underlying Parkinson's disease. The compound has been tested for this condition as well.

Sathirapongsasuti's data suggested that the PheWAS approach could be useful in drug development - and helped to convince 23andme that it should invest in its own drug programme. Using the results of additional phenome-wide association studies, Scheller and his team have now decided to focus on seven drug targets in four categories of disease: cancer, cardiovascular disease, skin disease and immune disorders, such as asthma.

Most scientists no longer see 23 andme as a frivolous undertaking. The ability to recruit two million customers, and potentially many more, has been a huge draw, and researchers are lining up to collaborate with the company. Other major biobanks can boast no more than

\section{"THE IDEA OF DEVELOPING DRUGS AS A RESULT OF GENETICS ISN'T AS STRAIGHTFORWARD AS MANY OF US WOULD LIKE."}

half a million people in their ranks. "They have the power of ' $N$ ', says cardiologist Eric Topol, director of the Scripps Translational Science Institute in La Jolla, California.

In October, the US National Institutes of Health awarded the company a \$1.7-million grant to sequence the genomes of hundreds of thousands of its African American customers who had already bought the company's standard product, which provides an overview of the genome rather than an in-depth analysis. The project - one of several sequencing initiatives that the company has started - is intended to help rectify the paucity of sequencing data on racial and ethnic minorities.

It's still an adjustment for scientists to work with 23 andme data, because the company asks its collaborators to follow unusual rules. Its agreement with customers forbids it from sharing their actual data with collaborators, so scientists see only the results of analyses run by the company and never have access to the raw data that inform the studies.
And some scientists are uneasy about the self-reported data resulting from 23andme questionnaires. Neurogeneticist Ashley Winslow, for instance, who led a high-profile collaboration with Pfizer to identify genetic markers associated with depression, says that peer reviewers of the resulting paper were concerned about the veracity of 23 andme's customer data. They argued that people who said that they had been diagnosed with clinical depression might just have been feeling low on the day that they took the company's survey. Winslow's team ran internal studies on the validity of the data, such as analyses showing the percentage of people who also reported using selective serotonin re-uptake inhibitors. The analyses were sufficient to get the paper published, but such concerns will probably come up again.

"Some communities might still be more dubious and demand more from the data to prove its relevance," says Winslow, who is now at the University of Pennsylvania in Philadelphia. But, she adds, the results of a large study such as hers, which has since been validated by another large psychiatric genetics consortium, are encouraging more scientists to work with the company. "There is definitely an openness that didn't used to exist," Winslow says.

But that doesn't mean that 23andme's model will definitely lead to new drugs. Several high-profile drugs based on human-genetics research have failed to live up to their potential, or have failed entirely. In May, for instance, pharmaceutical company Amgen, based in Thousand Oaks, California, announced that its genetically targeted osteoporosis drug romosozumab raised the risk of heart disease by as much as $30 \%$ in a clinical trial with 4,000 people. "The idea of developing drugs as a result of genetics isn't as straightforward as many of us would like," Topol says.

The direct-to-consumer genetic testing market has been transformed since 23 andme's early years. And although it is a small slice of the genetesting market, it is expected to grow to $\$ 340$ million in the next five years (see 'Gene drive').

And a growing crop of genetic-analysis companies are now competing for 23 andme's customers. They include firms offering inexpensive, targeted medical sequencing (Color Genomics in Burlingame, California); ancestry testing (Ancestry DNA, based in Salt Lake City, Utah); whole-genome sequencing, either on its own (Veritas, based in Danvers, Massachusetts) or in combination with medical testing (Craig Venter's Human Longevity in San Diego, California) or with apps for interpreting genomic data (Helix of San Carlos, California).

Wojcicki's competitors give her credit for showing that there may be a business in gathering and selling genetic data. "I'm a big admirer of 23 andme and what they've done for the entire industry in pioneering both consumer genetics and this difficult regulatory road," says Mirza Cifric, chief executive of Veritas. 23andme is still the only company offering FDA-approved direct-to-consumer health tests and no competitors have indicated a willingness to go down that path.

Wojcicki, for her part, still wants to stay ahead. "There's all kinds of ways we want to approach genetics," she says. For instance, 23 andme is watching closely as technology companies such as Apple and Google develop sensors and mobile health-data applications, and the company is looking for pilot projects in this space, which could allow it to seamlessly collect continuous data from its users. And she has no doubt that the company will achieve her goal of recruiting 10 million customers. "Just based on natural growth we'll get there," she says.

In the 23andme company cafeteria, the fun fact on Wojcicki's Polaroid picture seems at once trivial and telling: "I once ate so many carrots that I turned orange and was told not to eat carrots for a year."

Wojcicki's colour has come back. She took the advice. But whether her resolve and ability to correct course can also push 23 andme from earwax and ancestry to life-saving drugs remains an open question. If she has her way, it's her doubters who will one day become the real unicorns of Silicon Valley - so rare and shy, you'd hardly believe they exist.

Erika Check Hayden is a science journalist in San Francisco, California. 